Research article Open Access

\title{
CD44+/CD24- breast cancer cells exhibit enhanced invasive properties: an early step necessary for metastasis
}

\author{
Carol Sheridan ${ }^{1}$, Hiromitsu Kishimoto ${ }^{1}$, Robyn K Fuchs ${ }^{2}$, Sanjana Mehrotra ${ }^{3}$, Poornima Bhat- \\ Nakshatri4, ${ }^{4}$, Charles H Turner ${ }^{6}$, Robert Goulet Jr ${ }^{1}$, Sunil Badve ${ }^{3}$ and Harikrishna Nakshatri ${ }^{1,4,5,7}$
}

\author{
1Department of Surgery, Indiana University School of Medicine, Indianapolis, IN 46202, USA \\ 2Department of Anatomy and Cell Biology, Indiana University School of Medicine, Indianapolis, IN 46202, USA \\ ${ }^{3}$ Department of Pathology, Indiana University School of Medicine, Indianapolis, IN 46202, USA \\ 4 Walther Oncology Center, Indiana University School of Medicine, Indianapolis, IN 46202, USA \\ ${ }^{5}$ Walther Cancer Institute, Indianapolis, IN 46208, USA \\ ${ }^{6}$ Orthopedics Research Labs, Indiana University School of Medicine, Indianapolis, IN 46202, USA \\ ${ }^{7}$ Department Biochemistry and Molecular Biology, Indiana University School of Medicine, Indianapolis, IN 46202, USA \\ Corresponding author: Harikrishna Nakshatri, hnakshat@iupui.edu
}

Received: 17 Jul 2006 Revisions requested: 23 Aug 2006 Revisions received: 24 Sep 2006 Accepted: 24 Oct 2006 Published: 24 Oct 2006

Breast Cancer Research 2006, 8:R59 (doi:10.1186/bcr1610)

This article is online at: http://breast-cancer-research.com/content/8/5/R59

(C) 2006 Sheridan et al.; licensee BioMed Central Ltd.

This is an open access article distributed under the terms of the Creative Commons Attribution License (http://creativecommons.org/licenses/by/2.0), which permits unrestricted use, distribution, and reproduction in any medium, provided the original work is properly cited.

\begin{abstract}
Introduction A subpopulation (CD44+/CD24-) of breast cancer cells has been reported to have stem/progenitor cell properties. The aim of this study was to investigate whether this subpopulation of cancer cells has the unique ability to invade, home, and proliferate at sites of metastasis.

Methods CD44 and CD24 expression was determined by flow cytometry. Northern blotting was used to determine the expression of proinvasive and 'bone and lung metastasis signature' genes. A matrigel invasion assay and intracardiac inoculation into nude mice were used to evaluate invasion, and homing and proliferation at sites of metastasis, respectively.

Results Five among 13 breast cancer cell lines examined (MDAMB-231, MDA-MB-436, Hs578T, SUM1315, and HBL-100) contained a higher percentage $(>30 \%)$ of CD44+/CD24 cells. Cell lines with high CD44+/CD24- cell numbers express basal/ mesenchymal or myoepithelial but not luminal markers.
\end{abstract}

Expression levels of proinvasive genes (IL-1 $\alpha$, IL-6, IL-8, and urokinase plasminogen activator [UPA]) were higher in cell lines with a significant CD44+/CD24- population than in other cell lines. Among the CD44+/CD24-positive cell lines, MDA-MB231 has the unique property of expressing a broad range of genes that favor bone and lung metastasis. Consistent with previous studies in nude mice, cell lines with CD44+/CD24subpopulation were more invasive than other cell lines. However, only a subset of CD44+/CD24-positive cell lines was able to home and proliferate in lungs.

Conclusion Breast cancer cells with CD44+/CD24subpopulation express higher levels of proinvasive genes and have highly invasive properties. However, this phenotype is not sufficient to predict capacity for pulmonary metastasis.

\section{Introduction}

Stem cell theory proposes that cancers arise from malignant transformation of normal stem/progenitor cells [1-4]. The inherent properties of stem/progenitor cells may impart their transformed counterparts with the ability to evade traditional antitumor therapies and to establish metastasis [3-5]. Tumori- genic stem/progenitor cells have been documented in hematologic malignancies as well as in solid tumors [6-8]. Several studies implicated a subset of human breast cancer cells as having enhanced ability to form tumors in immunocompromised mice $[9,10]$. This subpopulation of cells also demonstrated a capacity for self-renewal and generation of

$\overline{\mathrm{ADAMTS}}=$ a disintegrin and metalloproteinase with thrombospondin; CTGF = connective tissue growth factor; CXCR $=\mathrm{CXC}$ chemokine receptor; $\mathrm{DMEM}=$ Dulbecco's modified eagle medium; ER = estrogen receptor; FCS = fetal calf serum; IL = interleukin; MMP = matrix metalloproteinases; $\mathrm{PBS}=$ phosphate-buffered saline; RANK = receptor activator of nuclear factor- $\kappa \mathrm{B} ; \mathrm{RT}-\mathrm{PCR}=$ reverse transcriptase polymerase chain reaction; UPA $=$ urokinase plasminogen activator. 
heterogeneous progeny. These cells were distinguished from their nontumorigenic counterparts by a specific cell surface marker profile: the CD44+/CD24//Lineage- However, the potential of these tumorigenic stem/progenitor cells to establish metastasis is not known.

Metastasis is a complex process that involves not only invasion but also homing and proliferation at sites of metastasis [11]. This process requires the activity of several genes, including the urokinase plasminogen activator (UPA)/UPA receptor system, cytokines (IL-1, IL-6, IL-8, IL-11, tumor necrosis factor, and transforming growth factor- $\beta_{1}$ ), chemokines and their receptors (stromal cell-derived factor- $1 \alpha$ and CXC chemokine receptor $[\mathrm{CXCR}] 4$ ), and matrix metalloproteinases (MMPs) [12-14]. Recent microarray analyses of clonal variants of MDA-MB-231 cells that home and grow at metastatic sites such as bone and lung have revealed a distinct gene expression pattern associated with metastasis to these sites $[14,15]$. Bone metastasis signature genes include CXCR4, connective tissue-derived factor (CTGF), IL-11, the metalloproteinase-disintegrin family member ADAMTS1 (a disintegrin and metalloproteinase with thrombospondin-1) and MMP1, whereas genes of the lung metastasis signature include CXCR4, MMP1 and cyclo-oxygenase-2. A recent study described the role of the receptor activator of nuclear factor-kB (RANK)/ RANK ligand in metastasis of breast cancer cells to bone [16].

Recent gene expression profiling has challenged the long held view that metastatic cells are rare and arise during later stages of tumor progression as a result of progressive accumulation of mutations. An alternative possibility is that most primary tumors contain a subset of cancer cells that has a 'metastatic phenotype' [17-19]. We investigated whether breast cancer cells with the CD44 ${ }^{+}$CD24 phenotype possess three essential characteristics of cells with metastatic phenotype: expression of invasion/metastasis-associated genes; invasion; and homing and proliferation at sites of metastasis. We show that a subgroup of breast cancer cell lines with a higher percentage of CD44+/CD24 cells express higher levels of proinvasive genes and invade matrigel in vitro. However, the CD44+/ CD24 phenotype is not sufficient for homing and proliferation at sites of metastasis.

\section{Materials and methods Breast cancer cell lines}

Except as indicated, breast cancer cell lines were obtained from American Type Tissue Culture Collection (Manassas, VA, USA). SUM1315 cells were obtained from Asterand (Detroit, $\mathrm{Ml}$, USA) and maintained in Dulbecco's modified eagle medium (DMEM)/F12 (CellGro, Herndon, VA, USA) containing $5 \%$ fetal calf serum (FCS), and supplemented with $10 \mu \mathrm{g} /$ $\mathrm{ml}$ insulin and $20 \mathrm{ng} / \mathrm{ml}$ epidermal growth factor. MCF-7, T47D, MDA-MB-231, MDA-MB-436, MDA-MB-468, SK-BR-3, Hs578T and HBL- 100 cells were grown in minimum essential medium containing 10\% FCS. ZR-75-1 and DU4475 cells were grown in RPMl containing 10\% FCS. MCF-10A cells were grown in DMEM/F12 media containing 5\% horse serum and the following supplements: $10 \mu \mathrm{g} / \mathrm{ml}$ insulin, $20 \mathrm{ng} / \mathrm{ml}$ epidermal growth factor, $100 \mathrm{ng} / \mathrm{ml}$ cholera euterotoxin, $0.5 \mu \mathrm{g} /$ $\mathrm{ml}$ hydrocortisone and $2 \mathrm{mmol} / \mathrm{l} \mathrm{L-glutamine.} \mathrm{BT474} \mathrm{cells}$ were grown in RPMl containing 10\% FCS, $2 \mathrm{mmol} / \mathrm{l} \mathrm{L}$ glutamine, $10 \mathrm{mmol} / \mathrm{l} \mathrm{HEPES}, 1 \mathrm{mmol} / \mathrm{l}$ sodium pyrophosphate, $4.5 \mathrm{~g} / \mathrm{ml}$ glucose, $1.5 \mathrm{~g} / \mathrm{ml}$ sodium carbonate, and 10 $\mu \mathrm{g} / \mathrm{ml}$ insulin.

\section{Flow cytometry}

Cells were washed once with phosphate-buffered saline (PBS) and then harvested with 0.05\% trypsin/0.025\% EDTA. Detached cells were washed with PBS containing 1\% FCS and $1 \%$ penicillin/streptomycin (wash buffer), and resuspended in the wash buffer $\left(10^{6} \mathrm{cells} / 100 \mu \mathrm{l}\right)$. Combinations of fluorochrome-conjugated monoclonal antibodies obtained from BD Biosciences (San Diego, CA, USA) against human CD44 (FITC; cat. \#555478) and CD24 (PE; cat. \#555428) or their respective isotype controls were added to the cell suspension at concentrations recommended by the manufacturer and incubated at $4^{\circ} \mathrm{C}$ in the dark for 30 to $40 \mathrm{~min}$. The labeled cells were washed in the wash buffer, then fixed in PBS containing $1 \%$ paraformaldehyde, and then analyzed on a FACSVantage (BD Biosciences).

\section{Northern analysis and reverse transcriptase polymerase chain reaction}

RNA was isolated using RNAeasy kit (Qiagen, Valencia, CA, USA) and $5 \mu \mathrm{g}$ RNA was subjected to Northern analysis, as described previously [20]. RT-PCR for IL-8 was performed using single step RT-PCR kit from Invitrogen (Carlsbad, CA, USA) and the following primers: 5'-GTA AAC ATG ACT TCC AAG CTG-3' and TTT TAT GAA TTC TCA GCC CTC-3'.

\section{Animal studies}

The Institutional Animal Care and Use Committee approved all animal studies. For intracardiac injection studies, $10^{5}$ cells were suspended in $100 \mu \mathrm{l}$ HEPES-buffered saline and slowly injected into the left cardiac ventricle of 7-week-old female nu/ nu mice using a 27-gauge needle (7 to 12 animals per cell type), as described previously [21]. Animals injected with TMD-231, LMD-231, or MDA-MB-468 cells were killed when they developed one or more of the following signs: hind limb paralysis from suspected spine metastasis, excessive weight loss, visible tumors, or labored breathing from lung metastasis. Lungs and bilateral axillary contents were collected in formalin for hematoxylin and eosin slide preparation. Animals injected with TMD-436 cells or DU4475 cells were killed 10 weeks after intracardiac injection. Lungs from animals injected with MDA-MB-468 cells (two animals) were digested with collagenase and hyaluronidase, and cancer cells were sorted by flow cytometry using PE-conjugated CD326 (EpCAM, \#130091-253; Miltenyi Biotech, Auburn, CA, USA) for enriching cancer cells. CD326-positive cells were evaluated for CD44 
and CD24 status immediately after sorting or 1 week after sorting.

\section{Matrigel invasion assay}

The invasion assay was performed as recommended by the manufacturer of the invasion assay kit (\#ECM554; Chemicon International, Temecula, CA, USA). Briefly, cells were serum starved for 24 hours and 50,000 cells were placed on the top insert with matrigel. Serum-free media or media with $10 \%$ serum were placed in the bottom well. The number of cells that invaded through the matrigel was calculated using fluorometric assay. For each cell line, the fluorometric reading from bottom wells with the serum-free media was defined as one unit to determine relative change in invasion in the presence of $10 \%$ serum. Each experiment contained one or two wells without serum and two wells with serum for each cell line. The experiment was repeated twice for most cell lines except for MCF-7, which was done thrice.

\section{Statistical analysis}

Data were analyzed with GraphPad software [22] to determine $P$ values using Fisher's exact test.

\section{Results \\ Human breast cancer cell lines differ quantitatively in the proportion of CD44+/CD24- cells}

To test the hypothesis that human breast cancer cell lines differ in the proportion of CD44+/CD24- cells, we characterized 13 breast cancer cell lines by flow cytometry for surface expression of CD44 and CD24. In addition to parental cell lines, derivatives of MDA-MB-231 and MDA-MB-436 cells were analyzed. TMD-231 cells were derived from MDA-MB231 cells grown in the mammary fat pad of nude mice. LMD231 cells were derived from MDA-MB-231 cells that had metastasized to lung from the mammary fat pad of nude mice [23]. TMD-436 cells were derived from MDA-MB-436 cells grown in the mammary fat pad of nude mice. A representative flow cytometry analysis of TMD-231, TMD-436, MCF-7, $\mathrm{Hs} 578 \mathrm{t}$, and BT474 cell lines showing expression patterns of CD44 and CD24 is shown in Figure 1. Isotype control for TMD-436 is shown, although isotype controls were conducted for all cell lines investigated. In Table 1 the results of this analysis are summarized with respect to four fractions defined by these two markers: CD44+/CD24-, CD44/CD24+, CD44+/CD24+, and CD44/CD24-. This table also shows the tumor type and tissue source, cell of origin, and molecular classification based on gene expression profiling or expression of markers [24-27]. According to this classification, CK19 is expressed predominantly in cell lines of luminal type whereas CK5, CD10, and ETS1 are expressed in cell lines of basal origin. Vimentin is expressed in cell lines of mesenchymal type. MDA-MB-231 and its derived cell lines TMD-436, Hs578T, SUM1315, and HBL-100 all possessed an increased CD44+/CD24- subpopulation (>30\%). The immortalized human breast epithelial cell line MCF10A also con- tained a CD44+/CD24- subpopulation. However, the percentage of the CD44+/CD24- subpopulation in this cell line varied markedly from experiment to experiment, and appears to be dependent on the serum used for cell culture. This was not the case with transformed cell lines. Also, note that the parental and tumor-derived variants of MDA-MB-231 and MDA-MB436 had similar CD44+/CD24- subpopulations.

\section{Breast cancer cell lines with significant CD44+/CD24- subpopulation express higher levels of genes associated with invasion}

To investigate the relationship between the CD44+/CD24 phenotype and proinvasive gene expression, Northern blot and/or RT-PCR analyses were performed. Genes in a recently described 'bone metastasis signature' (CXCR4, IL-11, CTGF, osteopontin, MMP-1, and ADAMTS1) and additional genes implicated in invasion/metastasis (IL-1 $\alpha, \mathrm{IL}-6, \mathrm{IL}-8$, and UPA) were included in this analysis $[12,14,15,21]$. The relationship between the size of the CD44+/CD24- population and expression of these genes is summarized in Figure 2a. Notably, only the MDA-MB-231 derivatives expressed all of the genes in the bone metastasis signature, although expression of IL-11 and CTGF was low or undetectable in the parental cell line compared with TMD-231 or LMD-231 cells. Although several cell lines expressed low levels of CXCR4, MDA-MB-231 and its derivatives exhibited the highest expression. This result was independently confirmed by flow cytometry. TMD-231 and LMD-231 cells expressed higher levels of CXCR4 (50\% to $70 \%$ ) than did any other cell line (data not shown). Twenty-five per cent of DU4475 cells expressed CXCR4. Of MCF-7 cells $5 \%$ to $8 \%$ expressed CXCR4 only when maintained in phenolred free-charcoal dextran treated media, whereas the rest of the cell lines did not exhibit cell surface CXCR4. MMP-1 expression was highest in Hs578T cells and the MDA-MB231 line and its derivatives. All other estrogen receptor (ER)$\alpha$-negative but not ER- $\alpha$-positive breast cancer cell lines expressed lower but detectable levels of MMP-1. All cell lines expressed similar levels of osteopontin, suggesting that its expression is not linked to the CD44+/CD24- phenotype.

Expression of additional proinvasive genes tested was observed predominantly in cell lines with an increased CD44+/ CD24- subpopulation. For example, expression of IL-1 $\alpha$, IL-6, and IL-8 was restricted to the cell lines MDA-MB-231, TMD231, LMD-231, MDA-MB-436, TMD-436, Hs578T, and HBL100; however, sensitive RT-PCR assay revealed IL-8 expression in several cell lines at variable levels (Figure 2a). Interestingly, tumor-derived or metastasis-derived variants of MDAMB-231 cells demonstrated enhanced expression of these genes as compared with parental cells; this finding suggests that cells expressing these genes at higher levels have enhanced tumorigenic potential. Although present in cell lines lacking CD44+/CD24- subpopulation, UPA expression was highest in cell lines with a higher fraction of the CD44+/CD24 subpopulation. Consistent with microarray analysis of primary 

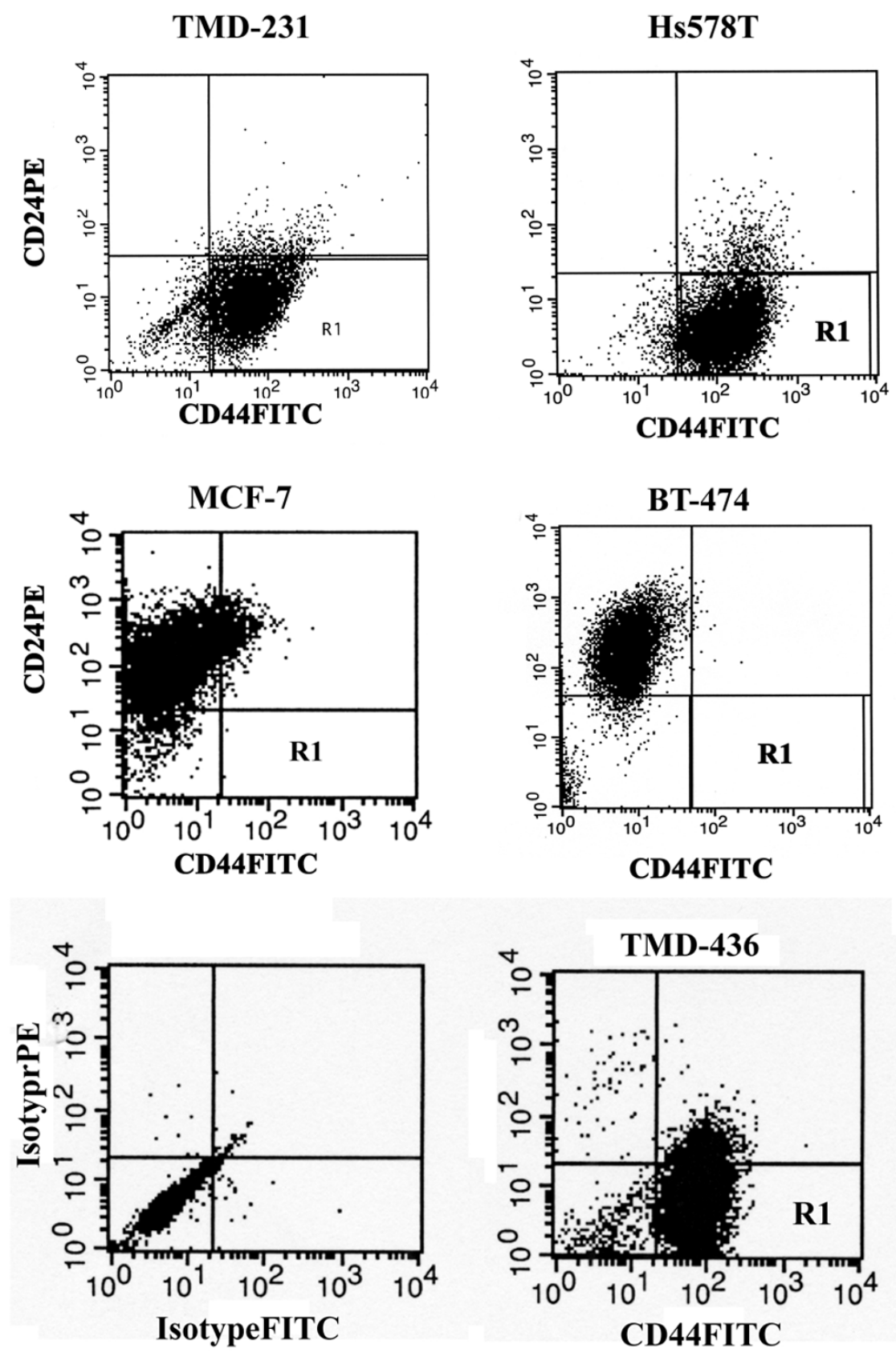

Identification of a CD44+/CD24- subpopulation in breast cancer cell lines by flow cytometry. Cells in R1 correspond to CD44+/CD24- cells. An isotype control corresponding to TMD-436 cells is shown.

breast cancers, overall expression of proinvasive genes was higher in ER- $\alpha$-negative cell lines than in ER- $\alpha$-positive cell lines $[28,29]$.

We then examined whether CD44+/CD24- and non-CD44+/ CD24- subpopulations of cells from a single cell line exhibit differential expression of proinvasive genes. Repeated attempts to culture CD44/CD24- subpopulation from TMD-231, which represents under $15 \%$ of cells, were not successful because of poor plating efficiency. Therefore, we isolated CD44+/ CD24- and CD44+/CD24+ cells from TMD-436 cells by flow cytometry (Figure $2 \mathrm{~b}$ ) and analyzed proinvasive gene expression either immediately by RT-PCR (data not shown) or after culturing for a week by Northern analysis (Figure 2c). CD44+/ 
Table 1

\begin{tabular}{|c|c|c|c|c|c|c|c|}
\hline Cell line & $\mathrm{CD} 44+/ \mathrm{CD} 24$ & $\mathrm{CD} 44^{+} / \mathrm{CD} 24^{+}$ & $\mathrm{CD} 44 / \mathrm{CD} 24^{+}$ & $\mathrm{CD} 44 / \mathrm{CD} 24$ & Tumor typea $[24,50-52]$ & $\begin{array}{l}\text { Tissue source } \\
{[24,50-52]}\end{array}$ & $\begin{array}{l}\text { Cell type } \\
\text { classification } \\
{[25-27]}\end{array}$ \\
\hline MDA-MB-231, TMD-231 & $85 \pm 5$ & 2 & 0 & $13 \pm 5$ & $\mathrm{AC}$ & Pleural effusion & Mesenchymal \\
\hline TMD-436 & $72 \pm 5$ & $27 \pm 5$ & 0 & 7 & $A C$ & Pleural effusion & Myoepithelial \\
\hline Hs578T & $86 \pm 5$ & $10 \pm 5$ & 0 & $2 \pm 2$ & CS & Primary & Mesenchymal \\
\hline SUM1315 & $97 \pm 3$ & 0 & 0 & $3 \pm 3$ & IDAC & Metastatic nodule & Basal \\
\hline HBL-100 & $37 \pm 5$ & 8 & 2 & $52 \pm 6$ & Immortal & Milk & Myoepithelial \\
\hline MDA-MB-468 & $3 \pm 1$ & $90 \pm 6$ & $7 \pm 3$ & 0 & IAC & Pleural effusion & Basal \\
\hline MCF-7 & 0 & $8 \pm 3$ & $87 \pm 2$ & $6 \pm 2$ & IDAC & Pleural effusion & Luminal \\
\hline T47-D & 0 & 0 & $63 \pm 3$ & $37 \pm 2$ & IDAC & Pleural effusion & Luminal \\
\hline ZR-75-1 & 0 & 0 & $64 \pm 1$ & $36 \pm 1$ & IDAC & Ascites & Luminal \\
\hline BT-474 & 0 & 0 & $78 \pm 7$ & $22 \pm 7$ & IDC & Primary & Luminal/ErbB2+ \\
\hline SK-BR-3 & 0 & 0 & $84 \pm 1$ & $16 \pm 1$ & $A C$ & Pleural effusion & Luminal/ErbB2+ \\
\hline DU4475 & 0 & 0 & $6 \pm 1$ & $94 \pm 1$ & IDC & Cutaneous nodule & ND \\
\hline$M C F-10 A^{a}$ & $17 \pm 4$ & $5 \pm 3$ & $20 \pm 10$ & $58 \pm 20$ & Immortal & Fibrocyst & Basal \\
\hline
\end{tabular}

aPercentage of MCF10A cell progenitor and other subpopulation was influenced by species and batch of serum in culture media. AC, adenocarcinoma; CS, carcinosarcoma; IDAC, infiltrating ductal adenocarcinoma; IAC, Invasive adenocarcinoma; IDC, Invasive ductal carcinoma; ND, not determined.

CD24- and CD44+/CD24+ cells exhibited a modest difference in IL-8 but not MMP-1, IL-6, and UPA expression (Figure 2c). These results suggest that CD $44^{+} / \mathrm{CD} 24^{+}$cells retain expression of the proinvasive genes that we tested.

\section{Invasive property is restricted to breast cancer cell lines with CD44+/CD24- subpopulation}

Because only cell lines with a substantial fraction of CD44+/ CD24- cells consistently expressed proinvasive genes, we compared the invasive capacity of cell lines with or without CD44+/CD24 cells. We excluded the SUM1315 line from this assay because these cells require serum and epidermal growth factor for survival, and cannot be maintained in serumfree media for 24 hours. Whereas breast cancer cell lines without CD44+/CD24- cells lacked invasive capacity, those with CD44+/CD24- subpopulation (MDA-MB-231, MDA-MB-436, and $\mathrm{Hs578T}$ ) exhibited invasion (Figure $3 \mathrm{a}$ ). There was trend toward increased invasion by TMD-231 and TMD-436 cells compared with the respective parental cells (MDA-MB-231 and MDA-MB-436), although differences were not statistically significant. These results show that the CD44+/CD24- phenotype of breast cancer cells is associated with invasive capacity.

We also examined the invasive capacity of the CD44+/CD24 and CD44+/CD24+ subpopulations of TMD-436 cells. Interestingly, CD44+/CD24- cells were more invasive than were CD44+/CD24+ cells (Figure $3 \mathrm{~b}$ ). These results further support the association between CD44+/CD24- phenotype and invasion.
The CD44+/CD24- phenotype is not sufficient to establish pulmonary metastasis

To test the hypothesis that CD44+/CD24- phenotype is sufficient for the establishment of metastasis in vivo, we tested the ability of these cell lines to establish pulmonary metastasis after intracardiac injection. In addition to the requirement of invasive property, metastatic cells should have the following properties: survival in circulation, adherence to target organ, extravasation, and initiation of growth at the metastatic site. Intracardiac injection of cancer cells into nude mice allows assessment of the metastatic capacity of cancer cells subsequent to entry into circulation [14,15,21,30-33]. Nude mice injected with cells were monitored for visible symptoms of metastasis for up to 10 weeks. The metastasis pattern of each of the cell lines tested is summarized in Table 2. TMD-231 injected animals exhibited signs of metastasis as early as 6 weeks, with most animals affected by 10 weeks. Metastatic growth was detected in vertebrae, limbs, chest wall, sternum, jaw, and scapula. Histologic staining further revealed metastatic growths in lungs (Figure 4a). Bone and visceral organ metastasis was further confirmed by dual energy X-ray absorptiometry scans and high-resolution Faxitron images (Figure 4b) and necropsy. Note that animals injected with either parental MDA-MB-231 or LMD-231 cells exhibited a similar pattern of metastasis (data not shown). Although without bone metastasis, animals injected with MDA-MB-468 cells had severe morbidity and mortality. In contrast, animals injected with parental MDA-MB-436, TMD-436, Hs578T, SUM1315, or DU4475 cells did not show any symptoms of metastasis even 10 weeks after intracardiac injection. A representative Faxitron image of 
Figure 2

(a)

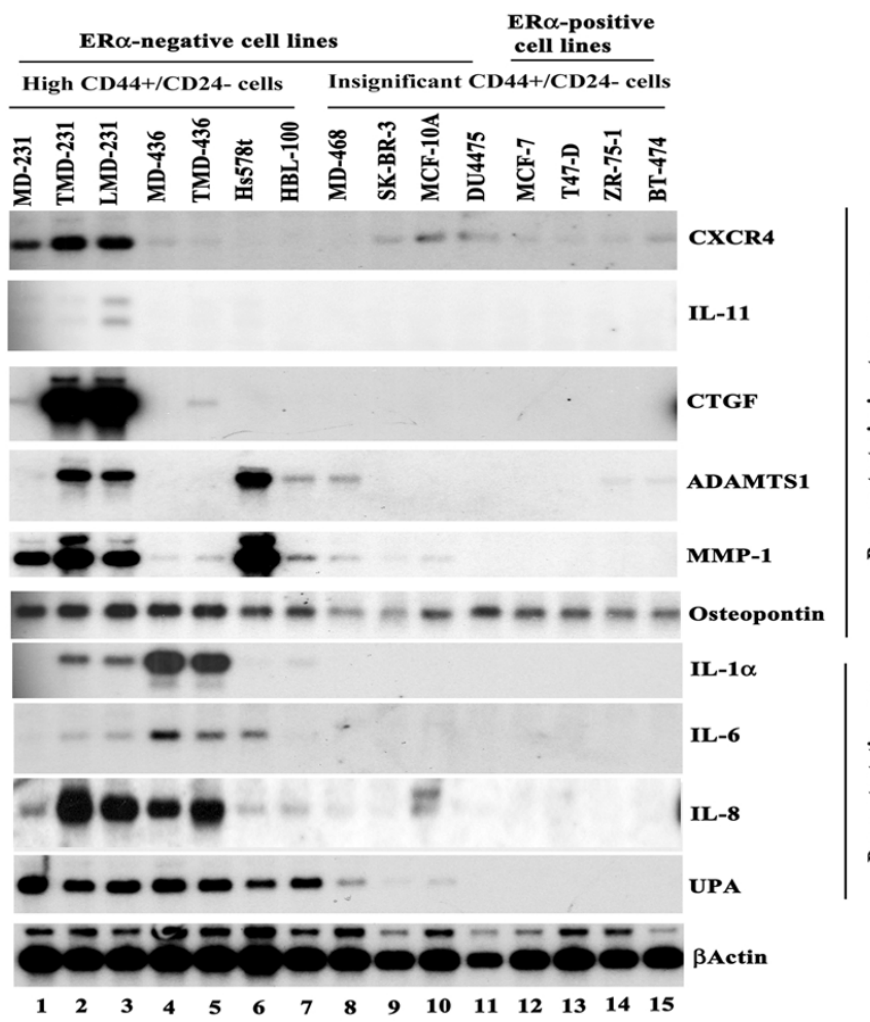

(b)

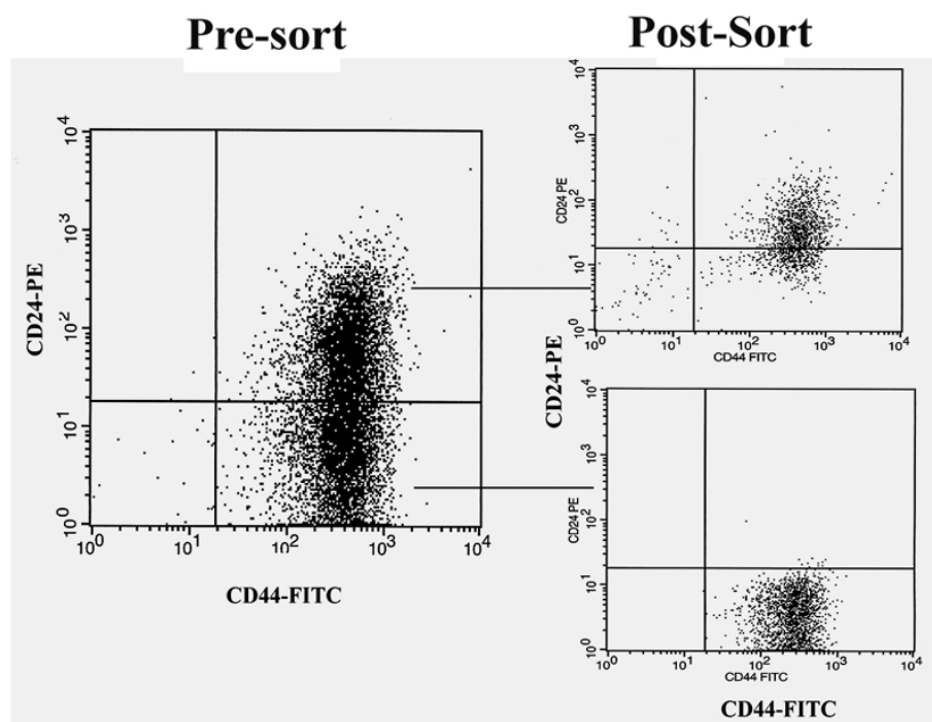

(c)

TMD-436

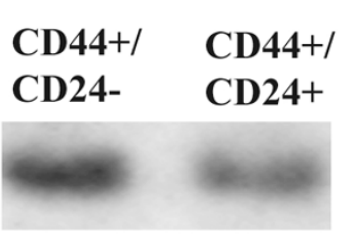

IL-8

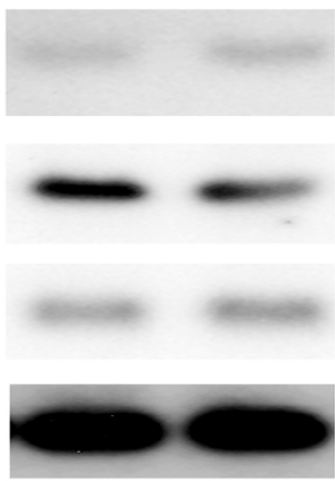

MMP-1

UPA

IL-6

36B4

Proinvasive and 'bone metastasis signature' gene expression patterns in cell lines with variable CD44+/CD24- subpopulation. (a) A representative Northern analysis of bone metastasis signature genes and proinvasive genes is shown. CD44+/CD24- status and ER- $\alpha$ expression pattern in cell lines are indicated. RT-PCR results of IL-8 and the control 36B4 are shown on the right. (b) CD44 and CD24 expression patterns in CD44+/CD24and CD44+/CD24+ subpopulations of TMD-436 sorted by flow cytometry. Expression in pre-sorted and post-sorted cells is shown. (c) Expression of IL-8, IL-6, MMP-1, and UPA in CD44+/CD24- and CD44+/CD24+ subpopulations of TMD-436 cells, as determined by Northern blot analysis. ER, estrogen receptor; MMP, matrix metalloproteinase; UPA, urokinase plasminogen activator. 


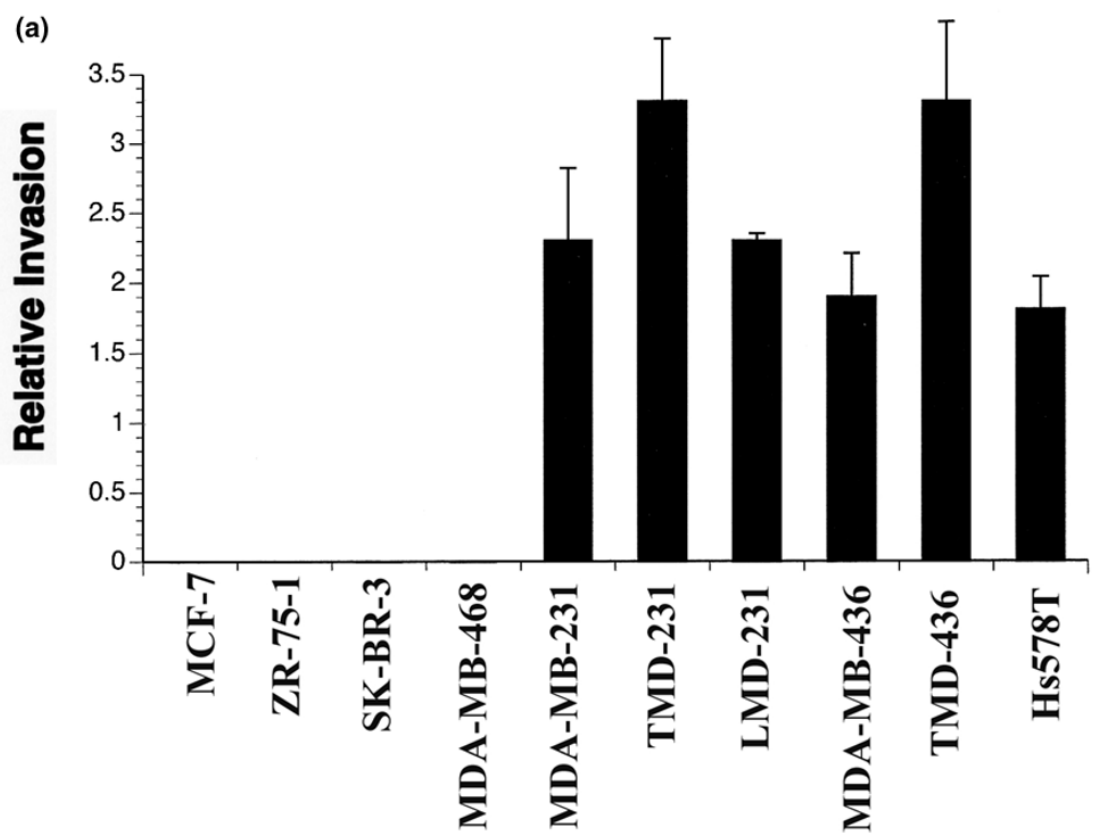

(b)

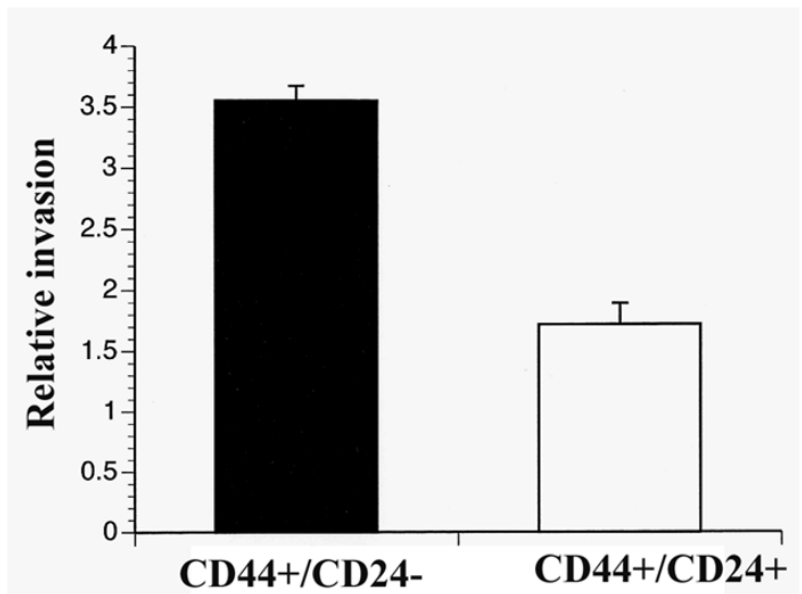

Cell lines with CD44+/CD24- subpopulation are highly invasive. (a) Matrigel invasion properties of breast cancer cell lines with or without CD44+/ CD24 subpopulation. Number of cells invaded through matrigel to serum-free media for each cell line was set as one unit and relative invasion to media containing 10\% fetal calf serum is shown. Mean and standard error of the mean is shown. Although invasion by TMD-231 and TMD-436 cells were higher than that of MDA-MB-231 and MDA-MB-436 cells, respectively, differences were not statistically significant. (b) Matrigel invasive properties of $\mathrm{CD} 44^{+} / \mathrm{CD} 24^{-}$and $\mathrm{CD} 44^{+} / \mathrm{CD} 24^{+}$subpopulations of TMD-436 cells. $P=0.006$.

an animal injected with TMD-436 cells is shown in Figure 4b. Lungs of animals injected with MDA-MB-468 or TMD-436 (6/ 8), but not Hs578T, SUM1315, or DU4475 cells, showed extensive growth of cancer cells (Table 2 and Figure 4a). Thus, the CD44+/CD24 phenotype, while associated with invasion, is not sufficient for establishment of metastasis.
Pulmonary metastasis of MDA-MB-468 cells is independent of expression of 'lung metastasis signature' genes

CD44+/CD24/Lin cells from primary breast cancers progress to $\mathrm{CD} 44^{+} / \mathrm{CD}_{24}{ }^{+}, \mathrm{CD} 44 \% \mathrm{CD} 24^{+}$, and CD44/CD24- phenotypes when implanted into mammary fat pad of nonobese diabetic/severe combined immunodeficiency mice [9]. However, whether CD44+/CD24- cells similarly progress to a heterogeneous population at sites of metastasis is not known. This possibility was explored using MDA-MB-231 (with 85\% CD44+/ 
Breast Cancer Research Vol 8 No 5 Sheridan et al.

Table 2

Metastasis pattern of breast cancer cell lines injected into nude mice via intracardiac route

\begin{tabular}{llll}
\hline Cell line & Bone metastasis & Gross lung metastasis & Histologic lung metastasis \\
\hline TMD-231 & $10 / 15$ & $0 / 15$ & $4 / 4$ \\
TMD-436 & $0 / 15$ & $4 / 15$ & $10 / 15$ \\
MDA-MB-468 & $0 / 10$ & $5 / 10$ & $8 / 8$ \\
SUM1315 & $0 / 11$ & $0 / 11$ & $0 / 11$ \\
Hs578T & $0 / 10$ & $0 / 10$ & $0 / 10$ \\
DU4475 & $0 / 8$ & $0 / 8$ & $0 / 8$ \\
\end{tabular}

CD24- subpopulation) and MDA-MB-468 cells (with <3\% CD44+/CD24 subpopulation). Cancer cells that metastasized to lungs were sorted and identified using CD326 antibody, which recognizes only human epithelial cells. CD44 and CD24 expression status in parental and lung metastasized cells (LMD-231 and LMD-468) were analyzed by flow cytometry. The CD44 and CD24 expression profiles of LMD-468 and LMD-231 cells were similar to those of the parental cells (Figure 5a and data not shown). Thus, at sites of metastasis, cancer cell phenotype based on CD44 and CD24 expression does not change significantly compared with that of parental cancer cells. Also, it is unlikely that few CD44+/CD24- cells of MDA-MB-468 cells contributed to lung metastasis and then progressed to become CD44+/CD24+.

We then examined whether LMD-468 cells express higher levels of lung metastasis signature genes than do parental cells. Lung metastasis signature genes were defined using clonal variants of MDA-MB-231 cells that grew in lungs after intracardiac injection [30]. All previously described lung metastasis signature genes that we tested were expressed in LMD-231 cells. In contrast, most of these genes were not expressed in both MDA-MB-468 and LMD-468 cells (Figure 5b). Also, TMD-436 cells, which grow in lungs, did not express the majority of the lung metastasis signature genes. These results suggest that the lung metastasis signature gene expression is not absolutely required for lung metastasis of breast cancer cells.

\section{Discussion}

\section{CD44+/CD24- phenotype of breast cancer cells is} associated with invasive properties

We investigated the importance of the stem/progenitor phenotype defined by CD44 positivity and CD24 negativity for breast cancer cells to invade and metastasize. Metastasis is a complex process that involves integrated activity of genes, which function in discrete steps that include the following: angiogenesis, invasion, intravasation, survival in circulation, extravasation, and homing and proliferation at sites of metastasis [19,34]. These genes include UPA/UPA receptor, MMPs, cytokines such as IL-1, IL-6, IL-8 and IL-11, parathyroid hormone-related peptide and the chemokine receptor CXCR4 $[12,14,21,31]$. Here we show that several of these genes are expressed in cell lines that contain significant numbers of CD44+/CD24- cells and that the expression pattern of these genes and the CD44+/CD24- phenotype correlates with invasive behavior of cell lines. However, the CD44+/CD24- phenotype is not sufficient for homing and growth at sites of metastasis. Thus, steps in the cascade of events required for the spread of cancer are dependent on distinct groups of genes, and the CD44+/CD24- phenotype may define the expression of the group of genes involved in invasion.

CD44 and CD24 have been shown to regulate invasion and metastasis of breast cancer cells either positively or negatively. Although most studies have shown CD44-mediated invasion of breast cancer cells [35,36], Lopez and coworkers [37] showed inhibition of breast cancer metastasis by this molecule. Similarly, CD24 has been shown to promote [38] or inhibit [39] invasion and metastasis of breast cancer cells. However, association of CD44+/CD24- phenotype with invasion observed in this study is not linked to the function of these genes because MDA-MB-468 cells expressing both CD44 and CD24 failed to invade. Also, the CD44+/CD24- subpopulation of TMD-436 was more invasive than the CD44+/CD24+ subpopulation of the same cell line (Figure $3 \mathrm{~b}$ ). Thus, the invasive property is intrinsic to cells of CD44+/CD24- phenotype. Which among the genes expressed in CD44+/CD24- cells confers the invasive phenotype is yet to be determined because CD44+/CD24- and CD44+/CD24+ subpopulations of TMD-436 cells exhibited modest differences in expression levels of the proinvasive genes tested but exhibited differences in invasion. In the original study on tumorigenic breast cancer progenitor cells [9] CD10 and CD140b were used as lineage markers, and so cancer cells expressing CD10 or CD140b were excluded from progenitor cells. However, several breast cancer cell lines that we examined express CD10 and it is considered a basal cell marker [25]. Studies are underway to determine whether the CD44+/CD24- subpopulation can be further subdivided based on the expression of markers such as CD10 and whether such subsets have unique invasion/metastasis properties. 
(a)

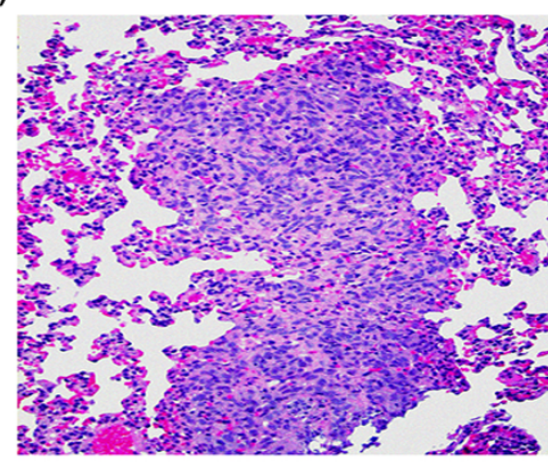

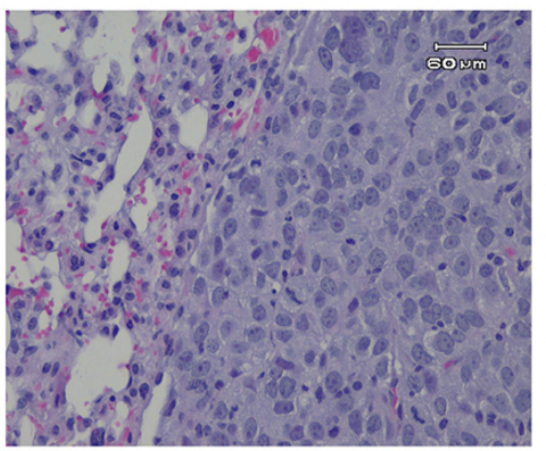

TMD-436
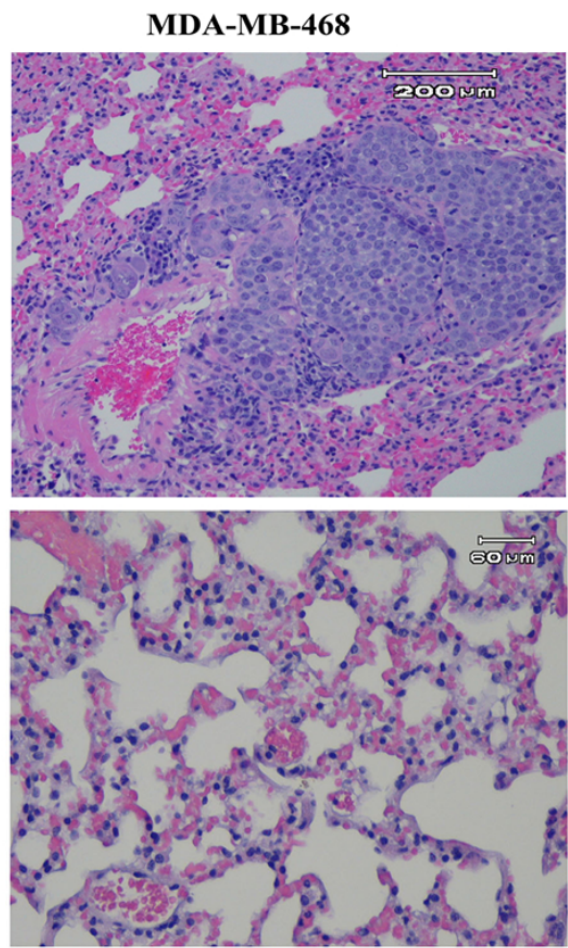

DU4475

(b)
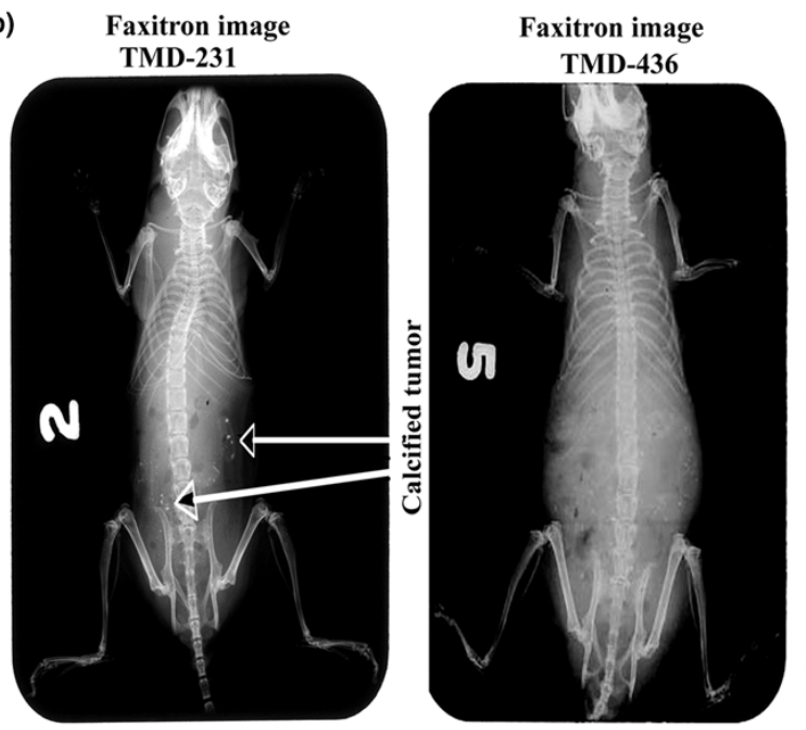

DXA Scan

TMD-231

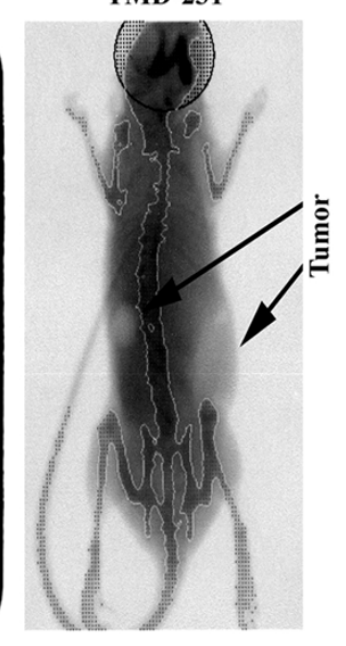

Lung metastatic properties of cell lines with or without CD44+/CD24- subpopulation. (a) Hematoxylin and eosin staining of lungs in animals injected with TMD-231, TMD-436, MDA-MB-468, and DU4475 cells. Metastasis was not observed with DU4475. (b) Faxitron images of calcified tumor growth in animals injected with TMD-231 but not with TMD-436 cells (left and center). Dual energy X-ray absorptiometry whole-body scan of an animal injected with TMD-231 cells is shown on right.

The invasive metastasis properties of several of the cell lines that we used in this study were examined by others before the identification of CD44+/CD24 cells, and most of these stud- ies correlated invasive properties with ER- $\alpha$ status and/or expression status of mesenchymal markers such as vimentin or MMPs $[24,40,41]$. These studies established a general 
Figure 5

(a)

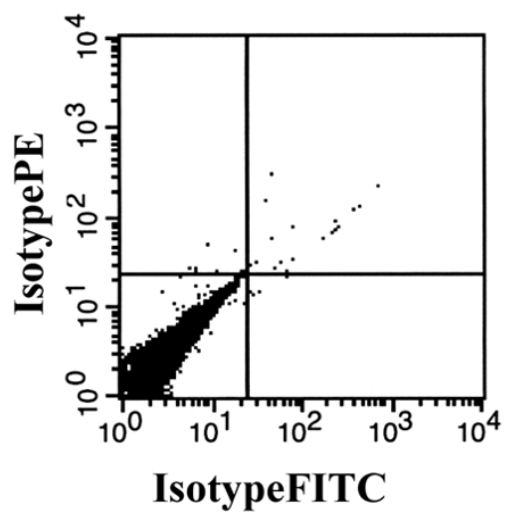

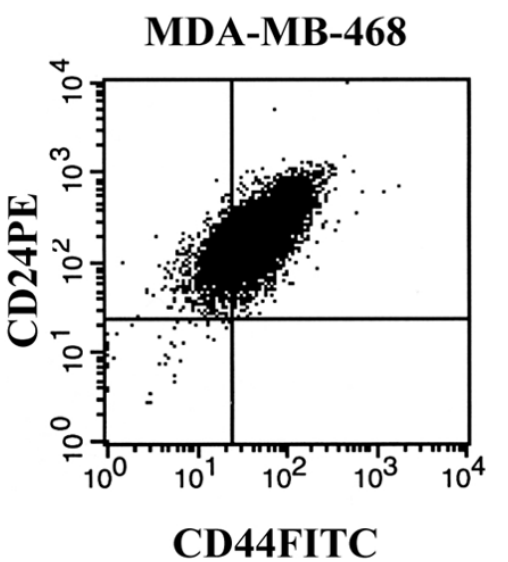

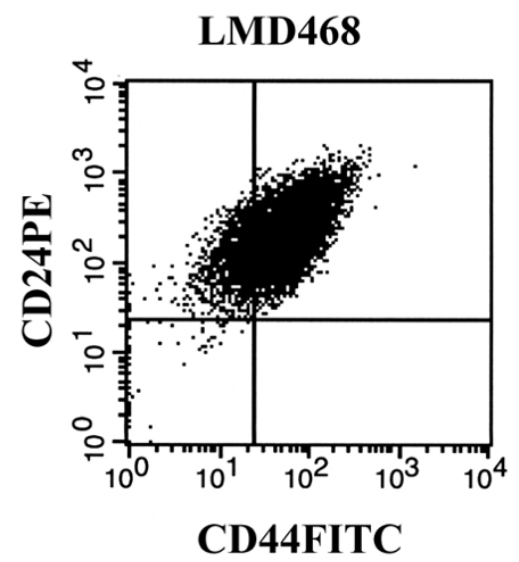

(b)

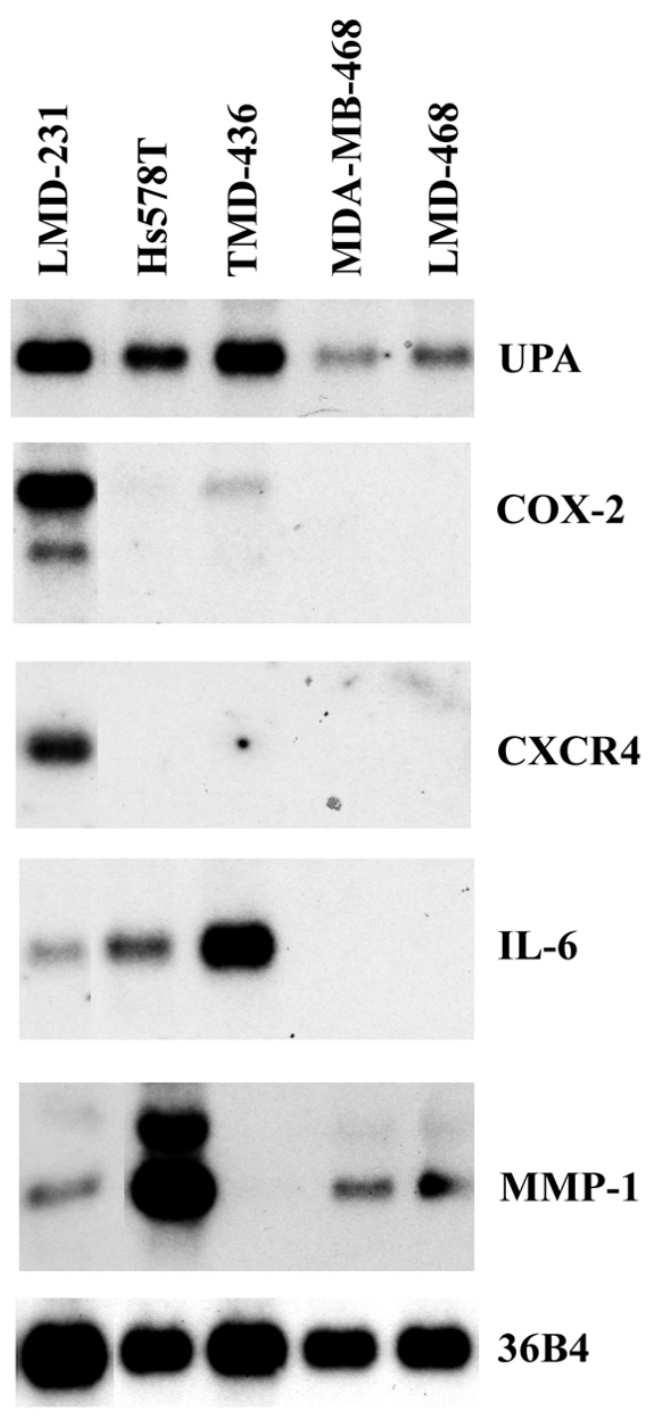

CD44 and CD24 status and lung metastasis signature gene expression in MDA-MB-468 and LMD-468 cells. (a) Flow cytometry showing CD44 and CD24 expression in MDA-MB-468 and LMD-468 cells. (b) Expression of select lung metastasis signature genes was determined by Northern blot analysis. COX, cyclo-oxygenase; CXCR, CXC chemokine receptor; MMP, matrix metalloproteinase; UPA, urokinase plasminogen activator. 
trend toward increased invasiveness of ER- $\alpha$-negative breast cancer cells. However, not all ER- $\alpha$-negative cells were invasive (MDA-MB-468 and SK-BR-3 cells, for example) [24,42]. Our study clearly shows a direct association between the CD44+/CD24 phenotype and invasion. However, neither our study nor previous studies revealed an association between homing and proliferation at sites of metastasis and ER- $\alpha$ status, mesenchymal marker expression, or CD44+/CD24- phenotype. For example, the ER- $\alpha$-positive and vimentin-negative cell line MCF-7 lacking CD44+/CD24- subpopulation forms osteosclerotic bone lesions on intracardiac injection in nude mice [32]. Similarly, we observed lung metastasis of MDA-MB468 cells, which are ER- $\alpha$ negative and vimentin negative, and lack a CD44+/CD24- subpopulation. In contrast, the vimentinpositive and ER- $\alpha$-negative cell line Hs578T, which has an $86 \%$ CD44+/CD24 subpopulation, failed to form lung metastasis. The minor difference in our results and previously published data with respect to hematogenous metastasis of Hs578T on mammary fat pad injection [24] is probably due to low frequency of metastasis (10\%). Also, we did not observe metastasis of SUM1315 cells, with a 97\% CD44+/CD24 subpopulation, in nude mice, although previous studies have shown bone metastasis of these cells in nonobese diabetic/ severe combined immunodeficiency mice with humanized but not mouse bone [43].

In a complementary study, Abraham and coworkers [44] reported that the prevalence of CD44+/CD24- cells (tumors with $>10 \%$ of CD44+/CD24 cancer cells) in $22 \%$ of tumor samples. The prevalence of these cells correlated with distant metastasis but no other clinical parameters. Our data suggest that the CD44+/CD24- population plays a critical role in the invasive step of metastasis. Thus, distant metastasis in patients with elevated levels of CD44+/CD24- cells may be related to enhanced invasiveness of cancer cells. It is possible that the establishment of growth at sites of metastasis is controlled by a distinct set of genes whose expression is unrelated to the CD44+/CD24 phenotype. An emerging opinion is that reduced expression of genes involved in cell-cell communication initiates invasion, whereas re-expression of genes involved in cell-cell communication is essential for survival and reattachment of metastases [45]. Therefore, metastatic growth may be primarily determined by signaling pathways that control the reexpression of cell-cell communication genes, which may be further influenced by the organ-specific microenvironment. In this regard, the transforming growth factor- $\beta$-activated signaling pathway is suggested to play a significant role in growth of cancer cells at sites of metastasis [13,14]. Although previous studies have identified lung metastasis signature genes using MDA-MB-231 cells as a model system [30], our studies reveal that the same set of lung metastasis signature genes is not involved in metastasis of MDA-MB-468 cells. Thus, additional studies are required to elucidate the mechanisms of tumor cell growth at sites of metastasis.

\section{CD44+/CD24- phenotype may define breast cancers of basal/myoepithelial origin}

Molecular profiling studies have classified breast cancers to five types with distinct prognostic significance: luminal type $A$, luminal type B, ErbB2-positive, normal-like, and basal type $[28,29]$. Patients with luminal type $A$ tumors have the most favorable prognosis, whereas patients with basal-type tumors have worst prognosis. Breast cancer cell lines have also been classified into five groups - luminal, basal, mesenchymal, ErbB2-positive, and myoepithelial - based on gene expression profiling [25,27]. As per gene expression profiling, basal and mesenchymal cells are similar except for differential expression of 227 genes. Interestingly, all cell lines that contained CD44+/CD24- population are in the basal/mesenchymal or the myoepithelial group (Table 1). Thus, stem/progenitor cells for luminal and ErbB2-positive breast cancers, which represent the majority of breast cancers, remain to be identified. In this regard, a 'side population' of cells with high drug efflux capacity has been described as cancer stem cells for breast cancer, lung cancer, and glioblastoma $[46,47]$. These side population cells have been identified in breast cancer cell lines of luminal type, and these cells overexpress transporter genes ABCG2 (ATP-binding cassette, subfamily G, member 2) and ABCA3 (ATP-binding cassette, subfamily A, member 3) [46]. Cells that express higher levels of CD24 in mouse are defined as luminal epithelial cells, and Lin-CD29hiCD24+ cells have been defined as mammary stem cells in mouse $[48,49]$. Note that all luminal cell types contain disproportionately higher levels of CD44/CD24+ cells (Table 1 ), and this population may contain cancer progenitor cells corresponding to luminal type of tumors. Identification of cancer stem cells specific for luminal cells, which represent about $70 \%$ of breast cancers, may allow improved understanding of signaling events that are involved in discrete steps of breast cancer progression, including metastasis.

\section{Conclusion}

In this report we show the relationship between $\mathrm{CD}_{4} 4^{+}$/ CD24 phenotype of breast cancer cells and discrete steps of the metastatic cascade. CD44+/CD24 phenotype is associated with enhanced invasive properties and elevated expression of genes involved in invasion. One surprising finding is the lack of correlation between CD44+/CD24- phenotype and ability to home and proliferate at sites of metastasis. Furthermore, our studies suggest that stem/progenitor cells defined by CD44 and CD24 identify tumorigenic progenitor cells corresponding to basal type.

\section{Competing interests}

The authors declare that they have no competing interests.

\section{Authors' contributions}

CS performed the analysis of cell lines for stem cell phenotype, Northern analysis, intracardiac injection, and necropsy of animals. HK performed intracardiac injection and trained oth- 
ers in this technique. RF and CHT conducted imaging studies. SM and SB were responsible for histology. PBN conducted Northern analysis and invasion assays. RG was involved in procuring primary tumor samples that were analyzed in parallel with cell lines. HN was involved in designing all experiments, performing flow cytometry, and writing the manuscript.

\section{Acknowledgements}

We thank Dr YC Yang for IL-11 cDNA, and SE Rice for assistance in flow cytometry. We thank Drs Edward Chen, Daniela Matei, and David Donner for critical reading of this manuscript. This work was supported by the grants from the American Institute for Cancer Research (03A069-REN), the National Cancer Institute (R01-CA89153) and Indiana University Cancer Center Pilot Grant (to HN). HN is Marian J Morrison Investigator in Breast Cancer Research.

\section{References}

1. Smalley M, Ashworth A: Stem cells and breast cancer: a field in transit. Nat Rev Cancer 2003, 3:832-844.

2. Dontu G, El-Ashry D, Wicha MS: Breast cancer, stem/progenitor cells and the estrogen receptor. Trends Endocrinol Metab 2004, 15:193-197.

3. Reya T, Morrison SJ, Clarke MF, Weissman IL: Stem cells, cancer, and cancer stem cells. Nature 2001, 414:105-111.

4. Behbod F, Rosen JM: Will cancer stem cells provide new therapeutic targets? Carcinogenesis 2005, 26:703-711.

5. Dean M, Fojo T, Bates S: Tumour stem cells and drug resistance. Nat Rev Cancer 2005, 5:275-284.

6. Jordan CT, Guzman ML: Mechanisms controlling pathogenesis and survival of leukemic stem cells. Oncogene 2004, 23:7178-7187.

7. Singh SK, Clarke ID, Hide T, Dirks PB: Cancer stem cells in nervous system tumors. Oncogene 2004, 23:7267-7273.

8. Valk-Lingbeek ME, Bruggeman SW, van Lohuizen M: Stem cells and cancer; the polycomb connection. Cell 2004, 118:409-418.

9. Al-Haji M, Wicha MS, Benito-Hernandez A, Morrison SJ, Clarke MF: Prospective identification of tumorigenic breast cancer cells. Proc Natl Acad Sci USA 2003, 100:3983-3988.

10. Ponti D, Costa A, Zaffaroni N, Pratesi G, Petrangolini G, Coradini D, Pilotti S, Pierotti MA, Daidone MG: Isolation and in vitro propagation of tumorigenic breast cancer cells with stem/progenitor cell properties. Cancer Res 2005, 65:5506-5511.

11. Chambers AF, Matrisian LM: Changing views of the role of matrix metalloproteinases in metastasis. J Natl Cancer Inst 1997, 89:1260-1270

12. Edwards DR, Murphy G: Cancer. Proteases: invasion and more [news]. Nature 1998, 394:527-528.

13. Dumont N, Arteaga CL: Targeting the TGF beta signaling network in human neoplasia. Cancer Cell 2003, 3:531-536.

14. Kang Y, Siegel PM, Shu W, Drobnjak M, Kakonen SM, CordonCardo C, Guise TA, Massague J: A multigenic program mediating breast cancer metastasis to bone. Cancer Cell 2003, 3:537-549.

15. Minn AJ, Kang Y, Serganova I, Gupta GP, Giri DD, Doubrovin M, Ponomarev V, Gerald WL, Blasberg R, Massague J: Distinct organ-specific metastatic potential of individual breast cancer cells and primary tumors. J Clin Invest 2005, 115:44-55.

16. Jones $\mathrm{DH}$ Nakashima $\mathrm{T}$ Sanchez $\mathrm{OH}$, Kozieradzkil, Komarova SV, Sarosi I, Morony S, Rubin E, Sarao R, Hojilla CV, et al:: Regulation of cancer cell migration and bone metastasis by RANKL. Nature 2006, 440:692-696.

17. Bernards R, Weinberg RA: A progression puzzle. Nature 2002, 418:823.

18. van 't Veer $L J$, Dai $H$, van de Vijver MJ, He YD, Hart AA, Mao M, Peterse HL, van der Kooy K, Marton MJ, Witteveen AT, et al:: Gene expression profiling predicts clinical outcome of breast cancer. Nature 2002, 415:530-536.

19. Pantel K, Brakenhoff RH: Dissecting the metastatic cascade. Nat Rev Cancer 2004, 4:448-456.
20. Bhat-Nakshatri $P$, Newton TR, Goulet R Jr, Nakshatri H: NF-kappaB activation and interleukin 6 production in fibroblasts by estrogen receptor-negative breast cancer cell-derived interleukin 1alpha. Proc Natl Acad Sci USA 1998, 95:6971-6976.

21. Bendre MS, Gaddy-Kurten D, Mon-Foote T, Akel NS, Skinner RA, Nicholas RW, Suva LJ: Expression of interleukin 8 and not parathyroid hormone-related protein by human breast cancer cells correlates with bone metastasis in vivo. Cancer Res 2002, 62:5571-5579.

22. Graphpad software [http://www.graphpad.com]

23. Helbig G, Christopherson KW II, Bhat-Nakshatri P, Kumar S, Kishimoto $H$, Miller KD, Broxmeyer HE, Nakshatri H: NF-kappaB promotes breast cancer cell migration and metastasis by inducing the expression of the chemokine receptor CXCR4. Biol Chem 2003, 278:21631-21638.

24. Thompson EW, Paik S, Brunner N, Sommers CL, Zugmaier G, Clarke R, Shima TB, Torri J, Donahue S, Lippman ME, et al:: Association of increased basement membrane invasiveness with absence of estrogen receptor and expression of vimentin in human breast cancer cell lines. J Cell Physiol 1992, 150:534-544.

25. Charafe-Jauffret E, Ginestier C, Monville F, Finetti $P$, Adelaide J, Cervera N, Fekairi S, Xerri L, Jacquemier J, Birnbaum D, et al.: Gene expression profiling of breast cell lines identifies potential new basal markers. Oncogene 2006, 25:2273-2284

26. Elstrodt $F$, Hollestelle A, Nagel JH, Gorin M, Wasielewski M, van den Ouweland A, Meraiver SD, Ethier SP, Schutte M: BRCA1 mutation analysis of 41 human breast cancer cell lines reveals three new deleterious mutants. Cancer Res 2006, 66:41-45.

27. Gordon LA, Mulligan KT, Maxwell-Jones H, Adams M, Walker RA, Jones JL: Breast cell invasive potential relates to the myoepithelial phenotype. Int J Cancer 2003, 106:8-16.

28. Sorlie T, Perou CM, Tibshirani R, Aas T, Geisler S, Johnsen H, Hastie T, Eisen MB, van de Rijn M, Jeffrey SS, et al.: Gene expression patterns of breast carcinomas distinguish tumor subclasses with clinical implications. Proc Natl Acad Sci USA 2001, 98:10869-10874.

29. Perou CM, Sorlie T, Eisen MB, van de Rijn M, Jeffrey SS, Rees CA, Pollack JR, Ross DT, Johnsen H, Akslen LA, et al:: Molecular portraits of human breast tumours. Nature 2000, 406:747-752.

30. Minn AJ, Gupta GP, Siegel PM, Bos PD, Shu W, Giri DD, Viale A, Olshen AB, Gerald WL, Massague J: Genes that mediate breast cancer metastasis to lung. Nature 2005, 436:518-524.

31. Mundy GR: Metastasis to bone: causes, consequences and therapeutic opportunities. Nat Rev Cancer 2002, 2:584-593.

32. Yi B, Williams PJ, Niewolna M, Wang Y, Yoneda T: Tumor-derived platelet-derived growth factor-BB plays a critical role in osteosclerotic bone metastasis in an animal model of human breast cancer. Cancer Res 2002, 62:917-923.

33. Hoffman RM: Orthotopic metastatic mouse models for anticancer drug discovery and evaluation: a bridge to the clinic. Invest New Drugs 1999, 17:343-359.

34. Edwards PA: Metastasis: the role of chance in malignancy. Nature 2002, 419:559-560.

35. Bourguignon LY: CD44-mediated oncogenic signaling and cytoskeleton activation during mammary tumor progression. $J$ Mammary Gland Biol Neoplasia 2001, 6:287-297.

36. Hill A, McFarlane S, Mulligan K, Gillespie H, Draffin JE, Trimble A, Ouhtit A, Johnston PG, Harkin DP, McCormick D, et al.: Cortactin underpins CD44-promoted invasion and adhesion of breast cancer cells to bone marrow endothelial cells. Oncogene 2006, 25:6079-6091

37. Lopez JI, Camenisch TD, Stevens MV, Sands BJ, McDonald J, Schroeder JA: CD44 attenuates metastatic invasion during breast cancer progression. Cancer Res 2005, 65:6755-6763.

38. Baumann P, Cremers N, Kroese F, Orend G, Chiquet-Ehrismann $R$, Uede T, Yagita H, Sleeman JP: CD24 expression causes the acquisition of multiple cellular properties associated with tumor growth and metastasis. Cancer Res 2005, 65:10783-10793

39. Schabath H, Runz S, Joumaa S, Altevogt P: CD24 affects CXCR4 function in pre-B lymphocytes and breast carcinoma cells. J Cell Sci 2006, 119:314-325.

40. Gilles C, Polette M, Zahm JM, Tournier JM, Volders L, Foidart JM Birembaut $P$ : Vimentin contributes to human mammary epithelial cell migration. J Cell Sci 1999, 112:4615-4625. 
41. Gilles C, Bassuk JA, Pulyaeva H, Sage EH, Foidart JM, Thompson EW: SPARC/osteonectin induces matrix metalloproteinase 2 activation in human breast cancer cell lines. Cancer Res 1998, 58:5529-5536.

42. Price JE: Metastasis from human breast cancer cell lines. Breast Cancer Res Treat 1996, 39:93-102.

43. Kuperwasser C, Dessain S, Bierbaum BE, Garnet D, Sperandio $K$, Gauvin GP, Naber SP, Weinberg RA, Rosenblatt M: A mouse model of human breast cancer metastasis to human bone. Cancer Res 2005, 65:6130-6138.

44. Abraham BK, Fritz $P$, McClellan M, Hauptvogel $P$, Athelogou $M$, Brauch H: Prevalence of CD44+/CD24-/low cells in breast cancer may not be associated with clinical outcome but may favor distant metastasis. Clin Cancer Res 2005, 11:1154-1159.

45. Cowin P, Rowlands TM, Hatsell SJ: Cadherins and catenins in breast cancer. Curr Opin Cell Biol 2005, 17:499-508.

46. Hirschmann-Jax C, Foster AE, Wulf GG, Nuchtern JG, Jax TW, Gobel U, Goodell MA, Brenner MK: A distinct 'side population' of cells with high drug efflux capacity in human tumor cells. Proc Natl Acad Sci USA 2004, 101:14228-14233.

47. Locke M, Heywood M, Fawell S, Mackenzie IC: Retention of intrinsic stem cell hierarchies in carcinoma-derived cell lines. Cancer Res 2005, 65:8944-8950.

48. Sleeman KE, Kendrick $H$, Ashworth A, Isacke CM, Smalley MJ: CD24 staining of mouse mammary gland cells defines luminal epithelial, myoepithelial/basal and non-epithelial cells. Breast Cancer Res 2006, 8:R7.

49. Shackleton M, Vaillant F, Simpson KJ, Stingl J, Smyth GK, AsselinLabat ML, Wu L, Lindeman GJ, Visvader JE: Generation of a functional mammary gland from a single stem cell. Nature 2006, 439:84-88

50. Langlois AJ, Holder WD Jr, Iglehart JD, Nelson-Rees WA, Wells SA Jr, Bolognesi DP: Morphological and biochemical properties of a new human breast cancer cell line. Cancer Res 1979, 39:2604-2613.

51. Gaffney EV: A cell line (HBL-100) established from human breast milk. Cell Tissue Res 1982, 227:563-568.

52. Soule HD, Maloney TM, Wolman SR, Peterson WD Jr, Brenz R, McGrath CM, Russo J, Pauley RJ, Jones RF, Brooks SC: Isolation and characterization of a spontaneously immortalized human breast epithelial cell line, MCF-10. Cancer Res 1990, 50:6075-6086 